\title{
SURVEI PROSES PEMBUATAN MINUMAN KAHWA DAUN DI PROPINSI SUMATERA BARAT, INDONESIA
}

\author{
Rilma Novita ${ }^{1}$, Anwar Kasim², Tuty Anggraini ${ }^{2}$, dan Deddi Prima Putra ${ }^{3}$ \\ ${ }^{1}$ Mahasiswa Pascasarjana Program Doktor Ilmu-ilmu Pertanian Universitas Andalas, \\ ${ }^{2}$ Fakultas Teknologi Pertanian Universitas Andalas \\ ${ }^{3}$ Fakultas Farmasi Universitas Andalas \\ Email: rilma.novita@yahoo.com
}

\begin{abstract}
ABSTRAK
Minuman kahwa daun adalah minuman yang terbuat dari daun kopi yang dikeringkan dan merupakan minuman khas Sumatera Barat. Survei proses pembuatan minuman kahwa daun telah dilakukan dengan mengunjungi tempat-tempat pembuatan minuman kahwa daun yang tersebar di tiga kabupaten yang ada di Sumatera Barat yaitu Kabupaten Tanah datar, Kabupaten Agam, dan Kabupaten Lima Puluh Kota. Penelitian ini bertujuan untuk mendapatkan informasi proses pembuatan minuman kahwa daun yang ada dan berkembang di Sumatera Barat. Data primer proses pembuatan minuman telah dikumpulkan dari 34 kedai atau kafe yang memproduksi dan menjual minuman kahwa daun yang terdapat di tiga kabupaten yang menjadi sentra budaya masyarakat Sumatera Barat (Minang). Pemilihan kedai atau kafe didasarkan pada kemudahan akses dan berada di pinggir jalan utama yang menghubungkan ketiga kabupaten. Data diperoleh dengan teknik wawancara, observasi langsung, dan dibantu daftar pertanyaan. Dari hasil pengamatan terhadap proses pembuatan minuman kahwa daun yang ada dan berkembang di Sumatera Barat diketahui bahwa ada tiga proses pembuatan minuman kahwa daun atau proses ekstraksi yaitu 1) pemasakan (air dan daun kopi dimasak secara bersamaan sampai mendidih) dikerjakan oleh 91,2 \% pembuat minuman kahwa daun, 2) penyeduhan (daun kopi diseduh dengan air panas $80-90^{\circ} \mathrm{C}$ ) dikerjakan oleh 2,9\% pembuat minuman kahwa daun, dan 3) pelarutan (air dimasak sampai mendidih kemudian daun kopi dimasukkan dan dibiarkan mendidih selama 3-5 menit), dikerjakan oleh 5,9\% pembuat minuman kahwa daun. Proses pembuatan minuman kahwa daun terbanyak dilakukan di Kabupaten Tanah Datar (52,9\%).
\end{abstract}

Kata kunci- ekstraksi; kahwa; minuman; survei

\section{PENDAHULUAN}

Minuman kahwa daun berasal dari Sumatera Barat dan dibuat dari daun kopi yang dikeringkan. Minuman kahwa daun menyerupai teh dengan warna air seduhan lebih gelap dari air teh dan disajikan dengan batok kelapa yang berfungsi sebagai gelas dan batok tersebut disangga dengan bambu. Sejarah pertama pembuatan minuman kahwa daun tidak diketahui secara pasti, namun menurut Hewitt (1872) daun tanaman kopi telah digunakan oleh masyarakat asli di kepulauan timur (eastern archipelago) sebagai teh. Mereka memanggang/menyangrai (roast) daun kopi di atas nyala api kecil kemudian saat daun dan ranting ini dilarutkan dengan air mendidih, mereka memperoleh minuman yang nikmat. Minuman ini telah lama berkembang di Sumatera dengan nama coffee-tea dan menarik perhatian ilmuwan kala itu. Dan Zed (2011) mengatakan bahwa orang Minang sudah mengenal tanaman kopi jauh sebelum kedatangan Belanda, dan daun kopi lebih penting daripada buahnya.

Penelitian terkait kahwa daun Sumatera Barat cukup banyak dilakukan. Beberapa penelitian yang telah dilakukan diantaranya penelitian kandungan total fenol dan aktivitas antioksidan minuman kahwa daun dan pengembangan kahwa daun menjadi produk instan seperti minuman kahwa daun mix, teh celup, dan serbuk kahwa daun. Minuman kahwa daun memiliki nilai total fenol 86,99-975,38 $\mathrm{mg} / \mathrm{L}$ dan aktivitas antioksidan dengan nilai inhibisi $51-80 \%$ terhadap aktivitas DPPH pada konsentrasi $50 \mu \mathrm{M}$. Salah satu faktor yang menyebabkan variasi kisaran nilai total fenol dan aktivitas antioksidan minuman kahwa daun adalah cara, waktu, dan suhu ekstraksi (Novita et al., 2016). Sementara itu penelitian terhadap minuman kahwa daun instan menunjukkan bahwa minuman kahwa daun dibuat melalui penyeduhan dengan air bersuhu $90^{\circ} \mathrm{C}$ (Novita et al., 2017).

Belum ditemukan standar operasi dalam proses pembuatan minuman kahwa daun sehingga produk minuman kahwa daun belum dapat bersaing sebagai produk minuman yang bermutu meski 
masyarakat meyakini minuman tersebut memiliki khasiat terhadap kesehatan. Sebagai langkah awal untuk melahirkan produk lokal yang berkualitas dan bermanfaat bagi kesehatan, maka perlu diketahui proses pembuatan minuman kahwa daun yang berkembang di masyarakat Sumatera Barat. Berdasarkan latar belakang ini maka dilakukanlah survei proses pembuatan minuman kahwa daun yang bertujuan untuk mendapatkan informasi awal proses pembuatan minuman kahwa daun yang ada dan berkembang di Sumatera Barat.

\section{METODOLOGI PENELITIAN}

\section{A. Waktu dan Tempat Penelitian}

Penelitian dilakukan pada bulan April-Juni 2017 dengan mengunjungi lokasi pembuatan dan penjualan minuman kahwa daun yang tersebar di tiga kabupaten yang ada di Sumatera Barat yaitu Kabupaten Tanah Datar, Kabupaten Agam, dan Kabupaten Lima Puluh Kota. Alasan pemilihan ketiga kabupaten adalah karena lokasi pembuatan dan penjualan minuman kahwa daun cukup banyak ditemukan di tiga kabupaten ini dan juga mewakili sentra budaya masyarakat Sumatera Barat (suku Minang). Pemilihan lokasi berupa kedai atau kafe yang akan disurvei didasarkan pada kemudahan akses dan letaknya yang berada di pinggir jalan utama yang menghubungkan ketiga kabupaten.

\section{B. Alat dan Bahan}

Alat bantu yang digunakan dalam survei berupa daftar pertanyaan, kamera, alat rekam suara dan GPS Mapping Garmin Oregon 550.

\section{Pelaksanaan Penelitian}

Penelitian dilakukan dengan metode deskriptif kualitatif. Data primer proses pembuatan minuman dikumpulkan dari 34 kedai atau kafe yang memproduksi dan menjual minuman kahwa daun. Pengumpulan data dilakukan dengan teknik wawancara, observasi langsung, dan diskusi. Hasil pengamatan dikelompokkan, dianalisa, dan dilaporkan.

\section{HASIL DAN PEMBAHASAN}

\section{A. Lokasi Penelitian}

Kabupaten Tanah Datar, Kabupaten Agam, dan Kabupaten Lima Puluh Kota adalah tiga kabupaten yang mewakili sentra budaya masyarakat Sumatera Barat (suku Minang). Lokasi pembuatan dan penjualan minuman kahwa daun berupa kedai atau kafe juga cukup banyak ditemukan di tiga kabupaten ini. Dengan menelusuri jalan utama yang menghubungkan ketiga kabupaten, telah dikumpulkan data kedai atau kafe yang membuat dan menjual minuman kahwa daun. Peta lokasi penelitian disajikan pada Gambar 1. Distribusi jumlah kedai atau kafe yang memproduksi minuman kahwa daun di setiap kabupaten dapat dilihat pada Tabel 1. Proses pembuatan minuman kahwa daun terbanyak dilakukan di Kabupaten Tanah Datar (52,9\%).

Tabel 1. Distribusi Jumlah Kedai/Kafe Minuman Kahwa Daun

\begin{tabular}{llc}
\hline No & Kabupaten & Jumlah Kedai/Kafe \\
\hline 1 & Tanah Datar & 18 \\
2 & Lima Puluh Kota & 12 \\
3 & Agam & 4 \\
\hline & Total & 34 \\
\hline
\end{tabular}




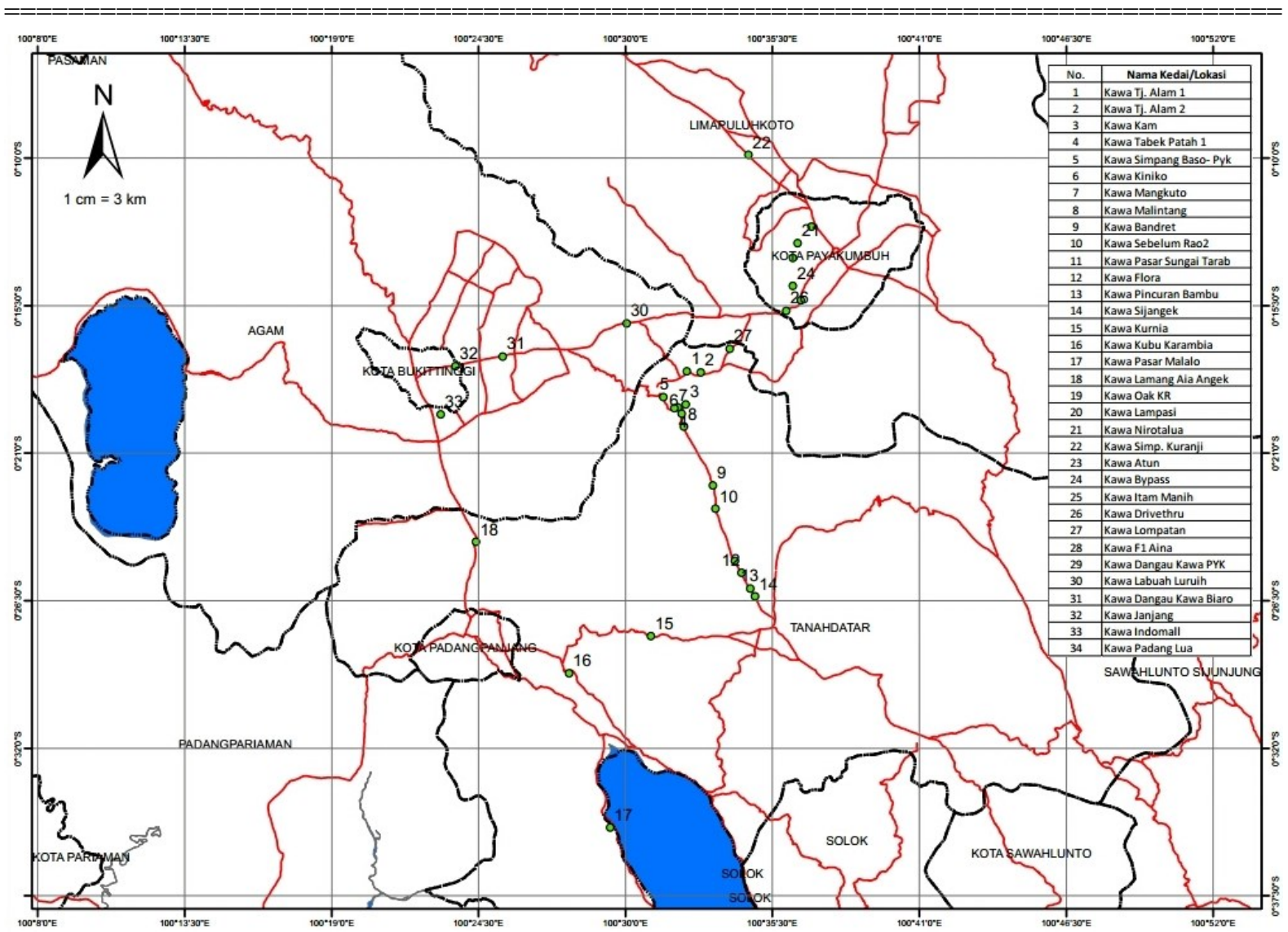

Gambar 1. Lokasi Penelitian Minuman Kahwa Daun

\section{B. Proses Pembuatan Minuman Kahwa Daun}

Pengelompokan proses pembuatan minuman kahwa daun di tiga kabupaten dilakukan setelah mempelajari seluruh hasil wawancara, observasi, dan diskusi yang dipandu daftar pertanyaan. Proses pembuatan minuman kahwa daun di masing-masing kabupaten memiliki perbedaan walau secara umum merupakan proses ekstraksi bahan alam. Menurut Agoes (2007), jumlah bahan yang akan diekstrak, derajat kehalusan bahan, waktu, suhu, dan proses ekstraksi adalah hal yang penting dalam pembuatan ekstrak. Ekstraksi bahan alam dengan menggunakan pelarut air dapat dilakukan dengan beberapa cara diantaranya decoctum, infusum, coque, seduhan, dan maserasi. Teh herbal adalah obat tanaman yang paling sederhana, infus yang dibuat dari satu atau campuran tanaman obat. Infus (infusum) adalah penarikan sari tanaman pada suhu $90-98^{\circ} \mathrm{C}$ menggunakan pelarut air selama 15 menit (Farmakope Belanda Edisi V dan VI). Seduhan adalah perendaman bahan dalam air panas selama 5-10 menit dan cara ini luas digunakan untuk jamu dan teh.

Dalam proses pembuatan minuman kahwa daun ditemukan variasi jumlah daun kopi yang digunakan dalam satu kali proses pembuatan minuman yaitu 20-50 g/L. Daun kopi yang digunakan dalam pembuatan minuman kahwa daun berupa serbuk kasar dan tidak dihaluskan (Gambar 2). Proses pembuatan minuman kahwa daun disajikan dalam Tabel 2.

Table 2. Proses Pembuatan Minuman Kahwa Daun

\begin{tabular}{lll}
\hline No & Kabupaten & \multicolumn{1}{c}{ Proses Pembuatan Minuman Kahwa Daun } \\
\hline 1 & Tanah Datar & $\begin{array}{l}\text { Air dan daun kopi dimasak secara bersamaan sampai mendidih (17) } \\
\text { Daun kopi diseduh dengan air hangat suhu sekitar } 90^{\circ} \mathrm{C}(1)\end{array}$ \\
2 & Lima Puluh Kota & $\begin{array}{l}\text { Air dan daun kopi dimasak secara bersamaan sampai mendidih (10) } \\
\text { Air dimasak sampai mendidih kemudian daun kopi dimasukkan dan } \\
\text { dibiarkan mendidih selama 3-5 menit (2) }\end{array}$ \\
& & Air dan daun kopi dimasak secara bersamaan sampai mendidih (4) \\
\hline
\end{tabular}

Angka dalam kurung menunjukkan jumlah kedai/kafe yang membuat dengan cara ini 
yaitu:

Proses pembuatan minuman kahwa daun dapat dikelompokkan menjadi tiga kelompok besar

1) Pemasakan (air dan daun kopi dimasak secara bersamaan sampai mendidih) dikerjakan oleh 91,2 $\%$ pembuat minuman kahwa daun,

2) Penyeduhan (daun kopi diseduh dengan air panas $90^{\circ} \mathrm{C}$ ) dikerjakan oleh $2,9 \%$ pembuat minuman kahwa daun, dan

3) Pelarutan (air dimasak sampai mendidih kemudian daun kopi dimasukkan dan dibiarkan mendidih selama 3-5 menit), dikerjakan oleh 5,9\% pembuat minuman kahwa daun.

Proses pembuatan minuman kahwa daun yang paling banyak dilakukan adalah dengan cara memasak air dan daun kopi secara bersamaan sampai mendidih dengan lamanya waktu pemasakan di setiap kedai/kafe bervariasi mulai dari 15-30 menit. Cara ini merata dilakukan di ketiga kabupaten. Menurut para peracik minuman kahwa daun, cara ini menghasilkan minuman kahwa daun dengan aroma dan rasa yang nikmat menyerupai kopi dengan warna air seduhan lebih pekat dari air teh.

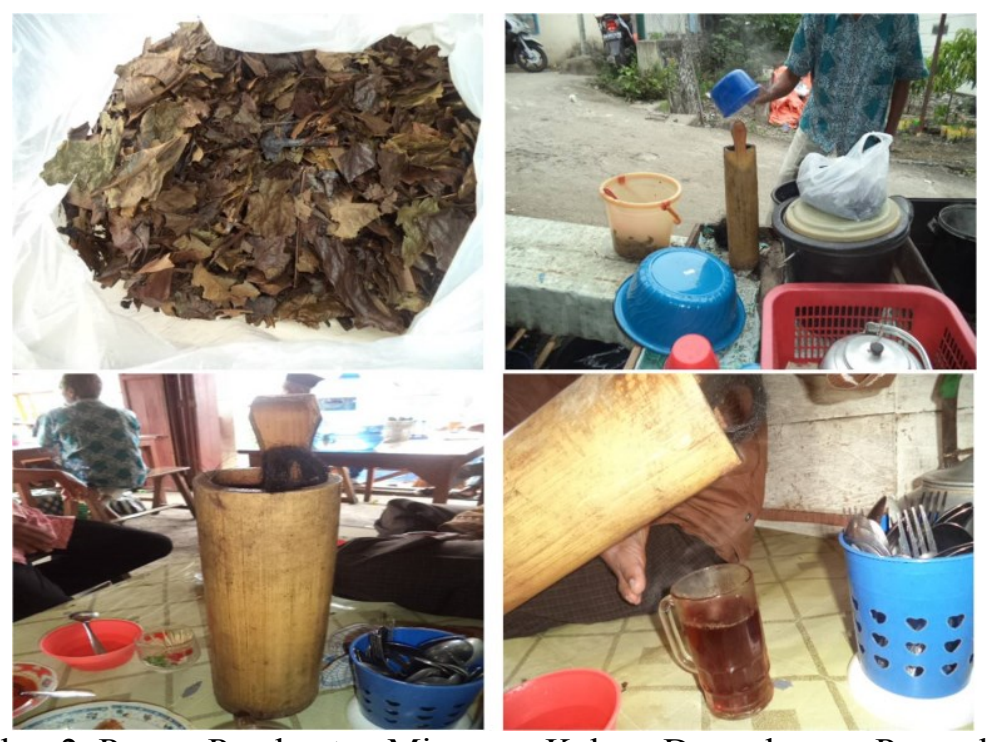

Gambar 2. Proses Pembuatan Minuman Kahwa Daun dengan Penyeduhan

Proses pembuatan minuman kahwa daun yang kedua (penyeduhan) hanya ditemukan di daerah Malalo, Kabupaten Tanah Datar. Daun kopi diseduh yang disebut perian/bamboo dan tutup perian terbuat dari ijuk. Cara penyeduhan ini telah diadopsi dalam penyeduhan kahwa daun kemasan celup dan produk instan berbasis kahwa daun. Dengan proses penyeduhan, kahwa daun yang dihasilkan memiliki warna air seduhan lebih terang daripada air seduhan kahwa daun yang dibuat dengan pemasakan. Minuman kahwa daun yang dihasilkan seperti teh (Gambar 3).

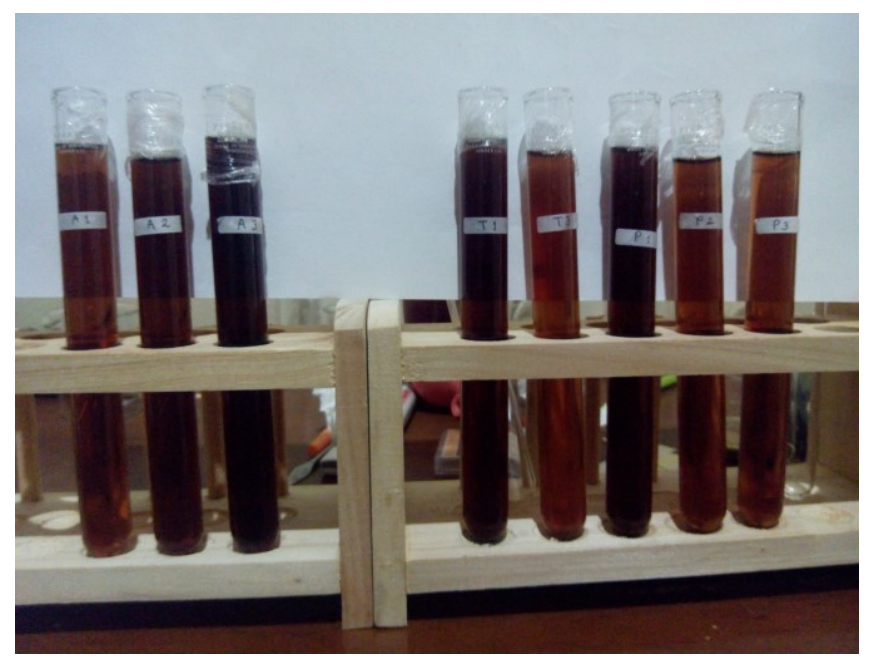

Gambar 3. Minuman Kahwa Daun dengan Variasi Proses Pembuatan 
Proses pembuatan kahwa daun yang ketiga ditemukan di Kabupaten Lima Puluh Kota yaitu memasak air sampai mendidih, setelah itu kahwa daun ditambahkan/dimasukkan. Minuman kahwa daun yang dihasilkan dengan cara ini memilki warna air seduhan lebih gelap dari teh tetapi lebih terang dari air seduhan hasil pemasakan. Kedai/kafe yang membuat minuman kahwa daun dengan cara pemasakan, dalam proses selanjutnya juga menggunakan cara ketiga ini yakni sekitar 24 kedai/kafe (70,6\%). Cara ini dilakukan dengan mencampur minuman kahwa daun yang sudah jadi dengan air sampai mendidih, kemudian daun kopi yang sudah diekstrak dipisahkan/dikeluarkan dan ditambahkan daun kopi yang baru.

Dari ketiga teknik ini belum diketahui karakteristik minuman kahwa daun yang dihasilkan. Untuk mendapatkan karakteristik minuman kahwa daun dengan sifat fungsional tertentu, perlu dilakukan penelitian lanjutan sehingga diperoleh rekomendasi metode terbaik dalam pembuatan minuman kahwa daun yang berkhasiat bagi kesehatan.

\section{KESIMPULAN}

Pembuatan minuman kahwa daun terbanyak dilakukan di Kabupaten Tanah Datar (52,9 \%) dan kahwa daun (teh herbal dari daun kopi) terbanyak diproduksi di Kabupaten Tanah Datar (75\%). Proses pembuatan minuman kahwa daun yang ada dan berkembang di Sumatera Barat meliputi tiga proses ekstraksi atau proses pembuatan minuman kahwa daun yaitu 1) pemasakan (air dan daun kopi dimasak secara bersamaan sampai mendidih) dikerjakan oleh 91,2\% pembuat minuman kahwa daun, 2) penyeduhan (daun kopi diseduh dengan air panas $80-90^{\circ} \mathrm{C}$ ) dikerjakan oleh $2,9 \%$ pembuat minuman kahwa daun, dan 3) pelarutan (air dimasak sampai mendidih kemudian daun kopi dimasukkan dan dibiarkan mendidih selama 3-5 menit), dikerjakan oleh 5,9\% pembuat minuman kahwa daun. Perlu dilakukan penelitian lanjutan sehingga diperoleh rekomendasi metode terbaik dalam pembuatan minuman kahwa daun sehingga dihasilkan minuman yang berkhasiat bagi kesehatan.

\section{DAFTAR PUSTAKA}

Agoes, G. 2007. Seri Farmasi industry Teknologi Bahan Alam. Bandung: Penerbit ITB.

Hewitt, Robert Jr. 1872. Coffee Its History, Cultivation and Uses. New York: D. Appleton and Company.

Novita, R., Eviza, A., Husni, J., Putri, S. K. 2017. Analisis Organoleptik Formula Minuman Kahwa Daun Mix. Jurnal Teknologi Pertanian Andalas. Vol. 21, No. 1, Maret 2017: 58-62 DOI 10.25077/jtpa.21.1.58-62.2017

Novita, R., Eviza, A., Putri, S. K. 2016. Kadar Fenol Total Dan Aktivitas Antioksidan Minuman Kawa Daun Di Sumatera Barat. Lumbung. Vol. 15, No. 2, Juli 2016: 156-161

Zed, Mestika. 2011. "Dilema Ekonomi Melayu : Dari Melayu Kopi daun Hingga Kapitalisme

Global.” Innovatio X (2): 209-23. 